\title{
JURISPRUDENCIA AMBIENTAL EN CASTILLA - LA MANCHA (SEGUNDO SEMESTRE 2019)
}

\author{
NuRIA MARÍA GARRIDO CUENCA \\ Profesor titular de Derecho Administrativo \\ Universidad de Castilla - La Mancha
}


Sumario: 1. El carácter normativo de los POGN y la exigencia de su publicación íntegra en el Diario Oficial. 2. Subvenciones: la modificación de una convocatoria de ayudas de agricultura ecológica en desarrollo de un Programa autonómico pendiente de ser debidamente aceptado por la Comisión Europea no supone infracción de los principios de confianza legítima ni seguridad jurídica. 3. Acceso a la información ambiental 4. Régimen sancionador:

\section{EL CARÁCTER NORMATIVO DE LOS POGN Y LA EXIGENCIA DE SU PUBLICACIÓN ÍNTEGRA EN EL DIARIO OFICIAL}

La Sentencia nำ131/2019, de 19 de abril del Tribunal Superior de Justicia de Castilla-La Mancha, (Sala de lo Contencioso-Administrativo, Sección 1 ${ }^{a}$ ) (RJCA 2019\199) estima el recurso interpuesto por la Asociación agraria de jóvenes agricultores de Castilla-La Mancha frente a la Orden 63/2017, de 3 de abril, de la Consejería de agricultura, medio ambiente y desarrollo rural, por la que se aprueba el Plan de gestión de las Zonas de Especial Protección para las aves de ambientes esteparios DOCM de 5 de marzo de 2017, número 67). La base fundamental del recurso era que la publicación en el DOCM se ha limitado a la mera aprobación del indicado Plan de Gestión de la Zona de Especial Protección ,que agrupa los espacios Red Natura 2000 que relaciona en el anexo, con otras previsiones que literalmente reproduce, pero remitiéndose, en cuanto a los documentos que meramente menciona y que integran el contenido del Plan de Gestión, a la página web de la Junta de Comunidades de Castilla-La Mancha, sin que dicho contenido haya sido objeto de publicación.

El Tribunal acoge la doctrina sobre esta cuestión ya dictada por el Tribunal Superior de Justicia de Andalucía, que recurrida en apelación fue confirmada en todos sus términos por el Tribunal Supremo. En efecto, "la técnica de original publicación de la norma" coincide con la llevada a cabo en la Comunidad Autónoma de Andalucía, en su Boletín Oficial de 2 de junio de 2015, que también aprueba planes de gestión y medidas de conservación de las ZEC que menciona, sin incorporar en la publicación el contenido de los documentos que integran ese Plan de Gestión. EI TSJA en Sentencia no 34/2017, de 12 de enero (recurso 477/2015), estimó el recurso contencioso planteado frente a la Orden de 11 de mayo de 2015, que realizó una publicación en los mismos términos que hace ahora nuestro Gobierno regional. 
La defensa de la administración autonómica mantiene que no debe prosperar el motivo de impugnación "puesto que la orden referida no tiene rango reglamentario", y ello en base a que "el plan de gestión objeto de recurso no puede conceptuarse como una disposición general, sino como un instrumento de planificación que contiene medidas de conservación, que conlleva la concreción o aplicación a un espacio determinado, materializando las medidas de conservación que el espacio demanda. Por tanto, el contenido del plan de gestión no se integra en el bloque normativo regulador de los espacios naturales ni viene a completar, desarrollar o pormenorizar las normas legales a las que se vincula, sino sólo a determinar las prescripciones en ellas previstas en tales leyes a unos espacios determinados que por sus valores naturales lo requieren, constituyendo una aplicación de la ley en el ámbito de la realidad física que acota y no un complemento a la misma que venga a introducir regulación en los espacios a los que las propia ley no ha alcanzado el .

Nuestro TSJCM desmonta este argumento en idénticos términos que el TSJ Andaluz, entendiendo en síntesis que estos planes son instrumentos normativos que por imposición del principio de publicidad de las normas deben ser objeto de publicación. Además, se apoya en la sentencia del Tribunal Supremo, Sala 3aㅡ, de 28 de enero de 2019 (RJ 2019, 199) cuyos razonamientos, por ser plenamente trasladables al debate planteado en nuestro caso, se reproducen, centrados en la cuestión de determinar la naturaleza que presentan y debe atribuirse a los Planes de Gestión de las ZEC, cuestión fundamental en orden a determinar su régimen de impugnación así como en orden a la obligatoriedad de su publicación o no en Diario Oficial correspondiente.

Según la doctrina jurisprudencial y aplicando la normativa, el Tribunal entiende que los que se denominan "adecuados planes de gestión" tienen por objeto cumplir con el deber impuesto a los Estados de establecer "las medidas de conservación necesarias", lo que significa que no se trata de previsiones programáticas o de orientación a la gestión preventiva y activa mediante el diálogo y concertación, como se mantiene por la Administración recurrente, sino de hacer efectiva la protección exigida en razón de la declaración de la ZEC. De hecho, en el contenido mínimo de estos, determinado normativamente, se establecen las medidas apropiadas para mantener los espacios en estado de 
conservación favorable; se exige atender las necesidades de determinados municipios o limitaciones singulares específicas ligadas a la gestión del lugar; o adoptar en dichos planes o instrumentos de gestión medidas apropiadas para evitar el deterioro de los hábitats naturales y de las especies. Por otra parte, establecidas estas previsiones en los planes de gestión, necesariamente ha de valorarse su compatibilidad con cualquier plan, programa o proyecto que pueda afectar de forma apreciable a las especies o hábitats de tales espacios ZEC. Por ello, señala el Tribunal, "no puede compartirse la interpretación de las normas efectuada por la Administración recurrente, para mantener que los planes de gestión en cuestión no tienen carácter normativo". Pues basta ver el contenido de los mismos y en concreto el que es objeto de este recurso para concluir que se trata del establecimiento de objetivos, medidas y criterios de actuación ejecutivos, que, "en cuanto se proyectan sobre los correspondientes espacios ZEC, afectan a quienes tienen titularidades e intereses en el ámbito de los mismos en los términos previstos y objeto de regulación en el Plan".

En consecuencia, rechazado este planteamiento, decae la alegación de no considerar exigible en este caso la obligación de publicación de las disposiciones de carácter general. Además, en este caso, esta previsión de carácter general se refuerza en la normativa específica que viene a indicar la necesidad de tal forma de publicidad de los planes de gestión. Así el art. 3 de la Ley 42/2007, dentro de las definiciones, señala en el número 22, que bajo la denominación de instrumentos de gestión se incluye cualquier técnica de gestión de un espacio natural y de sus usos, que haya sido sometido a un proceso de información pública, haya sido objeto de una aprobación formal y haya sido publicado. Previsión que ha de ponerse en relación con las Directrices de Conservación de la Red Natura 2000 en España, aprobadas por Acuerdo de la Conferencia Sectorial de Medio Ambiente (reunión de 13 de julio de 2011) publicadas por Resolución de 21 de septiembre de 2011, de la Secretaría de Estado de Cambio Climático, Ministerio de Medio Ambiente y Medio Rural y Marino (BOE № 244, 10 de octubre de 2011), conforme a las cuales se ha elaborado el Plan en litigio, según se recoge en su apartado 1.2, que establecen que los instrumentos de gestión deben estar sometidos a un procedimiento de aprobación formal, que debe culminar con su publicación en el correspondiente Boletín o Diario Oficial, 
añadiendo en el apartado B.3, que una vez publicado oficialmente el instrumento de gestión, el órgano responsable en materia de Red Natura 2000 lo notificará al Ministerio de Medio Ambiente y Medio Rural y Marino, a efectos de su comunicación a la Comisión Europea:

"Previsión de publicación que responde a la naturaleza de la disposición administrativa y las exigencias formales derivadas de su alcance y contenido, de acuerdo con las normas comunitarias e internas a las que responden dichas Directrices. Tal forma de publicación, por su alcance y contenido, no puede equipararse ni entenderse satisfecha en sus efectos por la remisión a la publicidad en otros medios, de acceso distinto e indirecto por parte de los destinatarios y afectados por la disposición, a salvo que la propia normativa reguladora del procedimiento de elaboración disponga esa forma específica de publicidad.

Es significativa al respecto la regulación que de la publicidad de los actos administrativos contiene la Ley 39/2015 de 1 de octubre, de Procedimiento Administrativo Común, distinguiendo entre notificación y publicación, facilitando las notificaciones con la aplicación de medios electrónicos mientras que la publicación de los actos, como es el caso de los planes de gestión, ha de realizarse, según dispone el art. 45.3, en el diario oficial que corresponda, según cual sea la Administración de la que proceda. En el mismo sentido el art. 131 sobre publicidad de las normas, establece la necesidad de publicación en el diario oficial correspondiente, sin perjuicio de que se establezcan otros medios de publicidad complementarios, es decir, que estos otros medios constituyen un elemento añadido de publicidad, pero no sustituyen la necesaria publicación en el diario oficial como requisito de elaboración de la disposición de que se trate".

Finalmente y en cuanto a la alegación relativa a la indebida aplicación de lo dispuesto en los arts. 62 y 63 de la Ley 30/92, al entender que en cualquier caso la falta de publicación del plan de gestión no sería causa de nulidad sino que afectaría únicamente a su eficacia, no tiene en cuenta la parte, que la sentencia recurrida en ningún momento declara la nulidad del Plan de Gestión, sino que la anulación se refiere a la Orden impugnada, por un vicio de la misma en cuanto no publica adecuadamente el Plan aprobado, de manera que la validez del Plan no se ve afectada por el pronunciamiento, sin perjuicio de que mientras no se 
publique adecuadamente carezca de la eficacia que depende de dicha publicación oficial.

2. SUBVENCIONES: LA MODIFICACIÓN DE UNA CONVOCATORIA DE AYUDAS DE AGRICULTURA ECOLÓGICA EN DESARROLLO DE UN PROGRAMA AUTONÓMICO PENDIENTE DE SER DEBIDAMENTE ACEPTADO POR LA COMISIÓN EUROPEA NO SUPONE INFRACCIÓN DE LOS PRINCIPIOS DE CONFIANZA LEGÍTIMA NI SEGURIDAD JURÍDICA

El Tribunal Superior de Justicia de Castilla-La Mancha, (Sala de lo ContenciosoAdministrativo, Sección $1^{1}$ ) se ha pronunciado en un nutrido grupo de sentencias sobre la legalidad de una norma estableciendo las bases para la concesión de subvenciones de agricultura ecológica en desarrollo del Programa de Desarrollo Rural y la posterior Resolución de ayuda. Sintetizamos aquí lo resuelto en una de las últimas, Sentencia num. 215/2019 de 15 julio (en igual sentido, Sentencia núm. 214/2019 de 15 julio. JUR 2019/265433 y Sentencia núm. 166/2019 de 20 mayo JUR $\backslash 2019 \backslash 265445$, entre otras muchas que no se acumularon en el proceso, debido a las diversas circunstancias y cuantías reclamadas).

Por centrar el objeto de recurso, este pretendía la desestimación por silencio administrativo del Recurso de Alzada interpuesto frente a la Resolución de la Dirección General de Desarrollo Rural de 24 de mayo de 2016, por la que se aprueba la solicitud inicial de la ayuda a la agricultura ecológica, submedida 11.2, mantenimiento de prácticas de agricultura ecológica, solicitud inicial año 2015, así como recurso indirecto contra la Orden de 7 de marzo de 2016 de la Consejería de Agricultura, Medio Ambiente y Desarrollo Rural por la que se modifica la Orden de 24 de marzo de 2015, por la que se establecen las bases reguladoras para la concesión de subvenciones para la aplicación de la medida de agricultura ecológica en el marco del Programa de Desarrollo Rural para Castilla-La Mancha 2014-2020, habiéndose ampliado el recurso contenciosoadministrativo a posterior resolución expresa de la Consejería de Agricultura, Medio Ambiente y Desarrollo Rural, desestimatoria del recurso de alzada interpuesto.

La discusión se plantea ante la Orden de 24 de marzo de 2015 que contenía las bases reguladoras de la subvención en lid, con la circunstancia de que pasados 
10 meses, y cerrado ya el plazo de solicitudes, la Consejería modifica las normas por Orden de 7 de marzo de 2016, que también es objeto de impugnación indirecta. Dicho gráficamente, la Consejería teniendo ya en su poder todas las solicitudes iniciales (fin del plazo de presentación es el 15 de mayo de 2015), conforme había previsto la convocatoria de 2015, dicta la Orden de 7 de marzo de 2016 y con ello cambia "las reglas del juego". En apoyo al suplico de nulidad de estas disposiciones se alega: la actuación arbitraria y contraria al principio de seguridad jurídica; una aplicación retroactiva de normas restrictivas de derechos en base únicamente al cambio de orientación política del Gobierno Regional respecto de la medida de agricultura ecológica y con ello cambia "las reglas del juego" torticeramente; quiebra de los principios de buena fe y confianza legítima, en tanto la Administración vulnera el principio de seguridad jurídica al romper los compromisos adquiridos con el solicitante de la subvención que confía en que aquella mantendrá los requisitos y extremos de las bases de la convocatoria para el 2015 y sucesivos. De modo, que a juicio del recurrente, no se trata de probar suerte con un nuevo proyecto, sino que se trata del mantenimiento de una actividad agrícola de prácticas de agricultura ecológica. Y aunque no se discute en este procedimiento el cumplimiento de los requisitos para ser beneficiario, lo que se rompe con la aplicación de las nuevas disposiciones son los compromisos rigurosos e intensos que obligan a los beneficiarios con la Administración, y que ahora ésta unilateralmente resuelve.

La Sentencia que analizamos trae a colación, por su indudable paralelismo, su anterior Sentencia de 23 de octubre de 2018, en la que se impugnaba directamente la Orden de 7 de marzo de 2016 citada, en tanto ha devenido firme al haberse inadmitido a trámite el recurso de casación que se interpuso contra ella (Providencia TS de 9 de mayo de 2019). En aquella, como en otras que la han sucedido se desestimó el recurso en una sólida fundamentación jurídica sobre cada uno de los aspectos.

1) La Orden de 2016 modificativa de la anterior tiene su habilitación legal en la disposición transitoria de esta en donde se establecía una condición suspensiva, de tal suerte que las ayudas de la medida de agricultura ecológica quedaban condicionadas a la aprobación definitiva del Programa de Desarrollo Rural de Castilla-La Mancha para el periodo de programación 2014-2020, por parte de la 
Comisión Europea; lo cual era coherente con el artículo 8.1, de la Orden modificada de 2015, que establecía el principio y procedimiento de concesión de ayudas sobre la base de concurrencia competitiva. La aprobación de este Programa en 30 de octubre de 2015 por la Comisión de la Unión Europea estableció que las ayudas previstas, en ningún caso sobrepasaran los límites de apoyo máximos establecidos en la reglamentación comunitaria (Reglamento (UE) n ${ }^{\circ}$ 1305/13, del Parlamento Europeo y del Consejo, de 17 de diciembre de 2013, relativo a la ayuda al desarrollo rural a través del Fondo Europeo Agrícola de Desarrollo Rural (FEADER), que establece que cuando existen disponibilidades presupuestarias suficientes para atender todas las solicitudes iniciales de ayuda, no será necesario determinar los criterios de prioridad; de aquí, que al no existir dicha disponibilidad suficiente, la anterioridad de gestión del Programa de Desarrollo, determinará los criterios de relación de operaciones teniendo en cuenta factores de eficiencia económica y medio-ambientales, previa consulta al comité de Seguimiento del mismo; presupuestos (determinación de la ayuda; concurrencia competitiva; y límite presupuestaria). Por ello, la Orden de 2016 está "justificada y racionalizada" y es obligada de acuerdo a las normas comunitarias. Por tanto, al tratarse de una subvención financiada con fondos comunitarios, es de aplicación el artículo 6 de la Ley 38/2003, de 17 de noviembre General de Subvenciones , a tenor del cual: "1. Las subvenciones financiadas con cargo a fondos de la Unión Europea se regirán por las normas comunitarias aplicables en cada caso y por las normas nacionales de desarrollo o transposición de aquéllas; 2. Los procedimientos de concesión y de control de las subvenciones regulados en esta ley tendrán carácter supletorio respecto de las normas de aplicación directa a las subvenciones financiadas con cargo a fondos de la Unión Europea".

El Tribunal también da respuesta al achaque referido a la discrecionalidad y límites de las Administraciones Públicas en el fomento de políticas públicas por medio de las subvenciones. Para entender que

"debe tenerse presente que el establecimiento de la subvención se inscribe, en principio, dentro de la potestad discrecional de la Administración y así lo resalta la sentencia del Tribunal Supremo de 3 de marzo de 1993 . Sin embargo, una vez que la subvención ha sido establecida y regulada normativamente, acaba la 
discrecionalidad administrativa y comienza la regla, porque su atribución concreta escapa del simple voluntarismo de la Administración, la cual debe atenerse a las bases y términos de la ayuda concedida. Ello supone que la convocatoria de una subvención, que la Administración efectúa mediante una disposición general, constituye una obligación que deben respetar no solo los aspirantes a la ayuda sino también la propia Administración mientras siga vigente la disposición constitutiva".( Sentencia de la Sala de lo Contencioso Administrativo del TSJ de Madrid, de 25 de mayo de 2017 )".

Y, en aplicación al caso de autos, que: "la Orden, de 07 de marzo de 2016, de la Consejería de Agricultura, Medio Ambiente y Desarrollo Rural de la Junta de Comunidades de Castilla-La Mancha, si bien es cierto que modifica la Orden de 24 de marzo de 2015, cuando había finalizado el plazo de presentación de solicitudes, también lo es, que lo hace antes de la resolución de las mismas, y, que la Orden modificada, condicionaba la concesión de las ayudas a la disponibilidad presupuestaria, estableciendo un régimen de concurrencia competitiva, amén de su carácter condicional, al estar supeditadas a la aprobación del Programa de Desarrollo Rural (PDR) para el periodo de programación 2014/2020".

Tampoco acoge la sentencia comentada la inaplicación retroactiva de normas y disposiciones restrictivas de derechos, tomando como base la jurisprudencia constitucional, en especial la sentada en la STC 49/2015, de 5 de marzo, dictada en relación a la suspensión de la revalorización automática de las pensiones operada por el Real Decreto-ley 28/2012, de 30 de noviembre (RCL 2012, 1635), donde resume la doctrina constitucional al respecto en su FJ 4 señalando que:

"a) Es doctrina reiterada de este Tribunal la de que el principio de irretroactividad de las leyes consagrado en el art. 9.3 CE "no es un principio general sino que está referido exclusivamente a las leyes ex post facto sancionadoras 0 restrictivas de derechos individuales. Fuera de estos dos ámbitos, nada impide constitucionalmente al legislador dotar a la ley del grado de retroactividad que considere oportuno, entre otras razones porque la interdicción absoluta de cualquier tipo de retroactividad conduciría a situaciones de congelación o petrificación del ordenamiento jurídico, lo que resulta inadmisible -ello, 
obviamente, sin perjuicio del debido respeto a otros principios consagrados en el art. 9.3 CE.

...c) Lo que el art. 9.3 CE prohíbe es "la incidencia de la nueva ley en los efectos jurídicos ya producidos de situaciones anteriores, de suerte que la incidencia en los derechos, en cuanto a su proyección hacia el futuro, no pertenece al campo estricto de la irretroactividad" ( STC 42/1986, de 10 de abril (RTC 1986, 42) ...la irretroactividad sólo es aplicable a los derechos consolidados, asumidos e integrados en el patrimonio del sujeto y no a los pendientes, futuros, condicionados y expectativas ...sólo puede afirmarse que una norma es retroactiva, a los efectos del art. 9.3 CE, cuando incide sobre "relaciones consagradas" y afecta a "situaciones agotadas"

En su aplicación al caso debatido, el TSJCM entiende que no es de recibo, pues la solicitud de la subvención de ayudas a la agricultura ecológica se caracteriza, desde el primer momento, por su concurrencia competitiva, lo que implica, " per se", que el solicitante no tiene derecho a la misma por el mero hecho de cumplir con las condiciones o requisitos establecidos en la norma de la subvención al ser necesario valorar las circunstancias que ya estaban prefijadas en la norma, esto es la disponibilidad presupuestaria y la condición suspensiva recogida en la Disposición Transitoria, en el sentido de que " quedan condicionadas a la aprobación definitiva del Programa de Desarrollo Rural de Castilla- La Mancha para el periodo de programación 2014/2020 por parte de la Comisión Europea, por lo que no se podrán resolver y notificar las resoluciones de incorporación a la ayuda, en tanto no se produzca la aprobación del referido Programa de Desarrollo Rural."

En definitiva, el tribunal sentenciará que el recurrente no resultaba acreedora de ningún derecho consolidado o consumado al percibo de la subvención, ni a que lo fuese por una cantidad concreta, por haber presentado la solicitud de subvención para la agricultura ecológica convocada al amparo de la Orden y Resolución de marzo de 2015, de tal forma que la Orden de 2016 no incurre en una retroactividad proscrita ( art. 9.3 CE ), pues no afectaba de forma desfavorable a ningún derecho adquirido e incorporado a su patrimonio una vez que el solicitante lo único que tenía era una expectativa condicionada a ser beneficiario de dicha ayuda. 
Respecto a la alegación de que la actuación de la administración quiebra los principios de buena fe y confianza legítima, al romper los compromisos suscritos con el solicitante de la subvención que confía en que aquélla mantendrá los requisitos y extremos de las Bases de la convocatoria para el 2015 y sucesivos. De nuevo con cita de la sentencia de TS Sala $3^{\underline{a}}$ de 26 abril de 2018, que sintetiza lo que denomina cuerpo de doctrina sobre el principio de "confianza legítima", perteneciente al ámbito de la seguridad jurídica y vinculado a otros principios como el de irretroactividad y protección de los derechos adquiridos, que por conocida no vamos a reiterar aquí, pero que "no permiten consagrar un pretendido derecho a la congelación del ordenamiento jurídico existente ( SSTC 182/1997, de 28 de octubre (RTC 1997, 182), FJ 13 , y 183/2014, de 6 de noviembre (RTC 2014, 183), FJ 3) ni, evidentemente pueden impedir la introducción de modificaciones legislativas repentinas, máxime cuando lo hace el legislador de urgencia ( STC 237/2012, de 13 de diciembre (RTC 2012, 237), FJ 6)"

En este sentido, la sentencia entiende que la norma modificada no afectaba de forma desfavorable a ningún derecho adquirido e incorporado a su patrimonio una vez que el solicitante lo único que tenía era una expectativa condicionada a ser beneficiario de dicha ayuda:

"en este caso, esa expectativa aparecía reflejada como tal y por tanto era o, cuanto menos ,podía haber sido conocida por el interesado, en la Orden de 24 marzo 2015, y más concretamente en su Disposición Transitoria, conforme a la cual las ayudas de la medida de agricultura ecológica que regula la orden " quedan condicionadas a la aprobación definitiva del Programa de Desarrollo Rural de Castilla-la Mancha para el periodo de programación 2014/2020 por parte de la Comisión Europea, por lo que no se podrán resolver y notificar las resoluciones de incorporación a la ayuda, en tanto no se produzca la aprobación del referido Programa de Desarrollo Rural".

Por último, en relación a la reducción arbitraria de las cuantías de las ayudas, también será desestimado en gran medida por los motivos antedichos, pues la modificación de la Orden impugnada se basa en el hecho de que los montantes han variado en la versión definitiva del Programa de Desarrollo Rural 2014-2020. Por lo que, de conformidad con la normativa europea, cualquier financiación 
debe estar incluida en el citado Programa aprobado por decisión comunitaria, por lo que cualquier subvención otorgada al margen del mismo estaría proscrita por la legislación europea.

\section{ACCESO A LA INFORMACIÓN AMBIENTAL}

La Sentencia no 10/2019 de 4 de febrero, del Tribunal Superior de Justicia de Castilla-La Mancha, (Sala de lo Contencioso-Administrativo, Sección 1a) $J U R \backslash 2019 \backslash 78061)$ resuelve sobre la desestimación por silencio de un recurso de alzada entablado por la asociación ecologista SEO contra Resolución de la Dirección General de Política Forestal y Espacios Naturales de fecha 18 de noviembre de 2015, entendiendo negados sus derechos de acceso a la información a los expedientes referentes a los Planes de Ordenación Cinegética y sus Resoluciones, incluidos los apartados de Planificación del aprovechamiento cinegético, Plan de vigilancia y número de vigilantes, y Plan de inversiones y jornales al año. En dicho recurso de alzada se hacía especial mención a la falta de respuesta relativa al trámite de evaluación de impacto ambiental, que decía debían pasar los Planes de Ordenación Cinegética ubicados en Red Natura 2000.

Frente a esta pretensión, la Junta de Comunidades de Castilla La Mancha en su contestación a la demanda, y acerca de la solicitud de información ambiental sobre Planes Técnicos de Caza "... de forma particular a la Evaluación de Impacto Ambiental" , argumenta que dicha solicitud obtuvo contestación en la resolución que obra en el expediente en la que en modo alguno se limitaba ese derecho, ya que la SAO siempre interviene en el trámite de información pública de ese procedimiento de Evaluación ambiental, en el que recibe copia del preceptivo y vinculante informe emitido por la Sección de Espacios Naturales, frente al que se le posibilita el trámite de alegaciones, que son valoradas al emitir la resolución que contiene la declaración de impacto ambiental, ante la que pueden interponer los recursos procedentes

Con estos antecedentes, la sentencia considera que no es arbitrario o contrario a la normativa de aplicación la limitación recogida en la resolución impugnada respecto al concreto contenido solicitado de los Planes Técnicos de Caza que afectan a la Red Natura 2000, y relativa al acceso e información acerca de la 
planificación del Aprovechamiento Cinegético, una vez que la SAO puede conocer todo el resto de información y datos que recoge el Plan Técnico en la que se hace referencia a todas aquellas cuestiones de interés verdaderamente medioambiental.

Además se indica que la SAO forma parte de tres órganos autonómicos colegiados esenciales en los que se discuten y deciden cuestiones sustanciales referentes al medio ambiente y a su posible afectación por medio de la actividad cinegética realizada en los acotados de Castilla-La Mancha: el Consejo Regional de Medio Ambiente, el Consejo Regional de Caza y los respectivos Consejos Provinciales de Caza, en cuyo seno sus participantes no sólo tienen cumplida información de toda la documentación ambiental que afecta a la Red Natura 2000, sino que participan en las decisiones adoptadas de forma colegiada, en muchos casos vinculantes para los órganos gestores, tanto en materia de caza como en materia de medio ambiente. La sentencia terminará con estos argumentos desestimando el recurso interpuesto por la asociación.

\section{4.- RÉGIMEN SANCIONADOR:}

\subsection{Procedimiento sancionador en materia de vías pecuarias}

La Sentencia no 154/2019, de 27 de junio, del Tribunal Superior de Justicia de Castilla-La Mancha, (Sala de lo Contencioso-Administrativo, Sección $2^{\text {a }}$ JUR\2019l268219) resuelve el recurso contencioso-administrativo contra la Resolución dictada por Consejo de Gobierno de la Junta de Comunidades de Castilla-La Mancha de fecha 21 de noviembre de 2017, por la que se acordó sancionar a AGRíCOLA HELLINERA, S.A., por la comisión de una infracción muy grave y otra grave en materia de vías pecuarias- Los hechos imputados a la parte demandante versan sobre la instalación de vallados y puertas metálicas en diferentes puntos de la vía pecuaria "Cordel del Camino Ancho", así como la plantación en la referida vía pecuaria de almendros con sistema de riego por goteo.

Parte la resolución impugnada de la base de que las vías pecuarias son bienes de dominio público y, en consecuencia, son inalienables, imprescriptibles e inembargables, de acuerdo con lo establecido en los arts. 2 de la Ley 3/1995, de 23 de marzo de Vías Pecuarias, y art.3 de su homóloga castellano-manchega, 
Ley 9/2003, de 20 de marzo. Y que por dicho carácter la Administración regional ostenta con respecto a las vías pecuarias una serie de facultades dirigidas a cumplir con las obligaciones que el ordenamiento jurídico le ha impuesto, relativas a: defensa de su integridad, garantía de su uso público, conservación y fomento de los valores compatibles con sus específicos fines, con el objeto de mejorar la calidad de vida, en las comunidades rurales y de sus visitantes. De entre dichas facultades destacan las referidas a la conservación y defensa de las vías pecuarias, que, como dice el art. 5 de la Ley regional, llevarán consigo las facultades de clasificación, deslinde, amojonamiento, desafección, así como cualesquiera otros actos dirigidos a este fin, lo que resulta sobre todo necesario cuando las vías pecuarias, clasificadas o no, sufran intrusiones por los propietarios colindantes, pero que, no por ello, dejan de ser bienes demaniales, dado su carácter de inalienables, imprescriptibles e inembargables.

En ese contexto, y en lo concernido a la clasificación de las vías pecuarias, dice la resolución recurrida que ésta supone aquel acto administrativo, de carácter declarativo, en virtud del cual se determinan la existencia, anchura, trazado y demás características físicas de cada una de ellas; y en nuestro caso, la vía pecuaria "Cordel del Camino Ancho", en el tramo II antes referido, figura entre las vías pecuarias clasificadas en el término municipal de Albacete mediante Proyecto de Clasificación aprobado por Orden Ministerial de 20 de enero de 1964. Una vez clasificadas, los límites de las vías pecuarias serán definidos a través del deslinde y de la delimitación, todos ellos actos de la Administración sujetos a Derecho Administrativo, que implican la existencia de un procedimiento que culmina con un acto aprobatorio por el cual la Administración, en el ejercicio de su potestad de autotutela, defiende, sin necesidad de acudir a la vía jurisdiccional, determinados bienes. Realizado el deslinde, y adquirida firmeza la resolución aprobatoria correspondiente en vía administrativa, se llevará a cabo el amojonamiento, procedimiento en virtud del cual se materializan con carácter permanente los límites de la vía pecuaria en el terreno.

La peculiaridad de este caso es que el deslinde del aludido tramo de la vía pecuaria, aprobado por resolución de 6 de agosto de 2008, fue anulado por STS de 14 de marzo de 2016 , al determinarse la caducidad del procedimiento de deslinde la de vía pecuaria. 
Según la resolución administrativa impugnada, la falta de deslinde de una vía pecuaria no conlleva, siempre y en todo caso, como pretendía la titular de las fincas que la habían ocupado con la colocación del vallado, cerramientos y plantaciones, la licitud y falta de responsabilidad de dichas ocupaciones. Y ello por cuanto que, según la jurisprudencia, lo relevante es la acreditación con medios probatorios suficientes de la real existencia de la vía pecuaria que ha sido objeto de intrusión, y, en ese sentido, la STS de 8 de octubre de 1999 , aun partiendo de la necesidad de que se practique el deslinde y amojonamiento de las vías pecuarias, determina que lo esencial es la prueba misma de la existencia de una vía que ha sido efectivamente ocupada.

También se impugnaba la nulidad del documento de iniciación de las actuaciones sancionadoras. $Y$ aunque es cierto que en el acuerdo de inicio del procedimiento sancionador, se alude al informe emitido por el Servicio de Medio Natural de la Dirección Provincial de Agricultura, sin que se hiciera mención a la identidad de las personas que emitieron el informe, entiende el Tribunal que, como ya se ha dicho en anteriores ocasiones "la denuncia (en este caso el informe del Servicio de Medio Natural) solo incurrirá en tal vicio si, habiéndose solicitado expresamente, la Administración no se la facilita al interesado", hecho este que no consta en el expediente ni se alega en la demanda. Y, acerca de la falta de indicación de la fecha en que los hechos se produjeron, solo cabe indicar que esos datos únicamente pueden hacerse constar en el supuesto de haber observado su producción en el momento de las visitas de inspección, pero no en los demás casos en que, como la propia parte actora viene a reconocer, las instalaciones y plantación objeto de la denuncia, ya se encontraban ejecutadas. Recuerda el Tribunal que "la jurisprudencia ha considerado relevante, en orden a la comisión de conductas típicas, en materia sancionadora de vías pecuarias, la acreditación con medios probatorios suficientes de la real existencia de la vía pecuaria que ha sido objeto de ocupación, afección o intromisión. $Y$, según la resolución recurrida, ha de concluirse que en este caso la vía pecuaria existe, y así era conocido por la interesada, en base a los datos que constan en el expediente"

También debe dilucidarse sobre si el cerramiento mediante vallado y colocación de una puerta transversal en una vía pecuaria constituye una infracción 
continuada. También recordando jurisprudencia previa, ya en la sentencia de 30 de diciembre de 2014 (recurso 628/2014), se declaró que: "En el caso de autos no estamos en el caso de infracción continuada sino de una infracción cuya ejecución se agota con la actuación material de instalación de la valla y puerta, la que a su vez puede durar un lapso de tiempo indeterminado; el tipo aplicado exige la acción material de poner el obstáculo en la vía pecuaria; a partir del momento en que finalice, se inicia el cómputo del plazo de prescripción; si el tipo hubiera sido de otro tenor, como por ejemplo "la ocupación sin autorización...", cabría pensar en la existencia de una infracción continuada; no es el caso .". Ahora bien, en el expediente existe constancia, lo que no ha sido objeto de contradicción, de que el vallado fue instalado en 1988, no existe constancia de la fecha en que se instaló la puerta cuyo cerramiento solicitó la parte recurrente con fecha 19 de noviembre de 2015, para que se le autorizase su cerramiento por las noches, lo que fue expresamente denegado por resolución del Director Provincial de Agricultura, Medio Ambiente y Desarrollo Rural, habiéndose manifestado por la recurrente, mediante escrito de 1 de marzo de 2016, que procedía a dar cumplimiento de la misma; y, sin embargo, en visita posterior funcionarios del Servicio constataron que la puerta se encontraba cerrada con un candado, por lo que, en el momento en que se acordó la incoación del procedimiento sancionador no había transcurrido el plazo de 5 años a que se refiere el art. 55 de la Ley 9/2003 para la prescripción de las infracciones muy graves.

Respecto al hecho de la inscripción registral de las fincas concernidas por el procedimiento sancionador a favor de la mercantil recurrente y a su inscripción a nombre de los anteriores titulares desde antes de la aprobación del Proyecto de Delimitación de la vía pecuaria, y aunque el deslinde había caducado, no es óbice para aplicar una sólida doctrina jurisprudencial que señala que:

" 1) Las vías pecuarias son bienes de dominio público, no susceptibles de prescripción ni de enajenación.

2) Las cuestiones sobre titularidad dominical definitiva de las mismas, ni son propias de un simple expediente de clasificación, ni en todo caso corresponde su resolución a los Tribunales de lo Contencioso-Administrativo. 
3) El deslinde aprobado declara la posesión y la titularidad demanial a favor de la Comunidad Autónoma, dando lugar al amojonamiento, y sin que las inscripciones del Registro de la Propiedad puedan prevalecer frente a la naturaleza demanial de los bienes deslindados. La resolución de aprobación del deslinde será título suficiente para rectificar, en la forma y condiciones que se determinen reglamentariamente, las situaciones jurídicas registrales contradictorias con el deslinde ".

El Tribunal cita además al respecto la STS de 24 de febrero de 2017 (RJ 2017, 1211) (recurso de casación 1167/2015), donde se examinaba un supuesto que guarda cierta analogía con el aquí analizado, donde el Tribunal Supremo decía lo siguiente:

" Con respecto a la protección registral y usucapión alegadas, insistir en que dice el Art. 7 de la Ley 3/95 de Vías Pecuarias, que la clasificación es el acto administrativo de carácter declarativo, en virtud del cual se determina la existencia, anchura, trazado y demás características de cada vía pecuaria, siendo el deslinde, según el art. 8, el acto administrativo por el que se definen los límites de las vías pecuarias, de conformidad con lo establecido en el acto de clasificación.

El citado art. 8 establece también, que el expediente de deslinde incluirá, necesariamente, la relación de ocupaciones, intrusiones y colindancias. El deslinde aprobado declara la posesión y la titularidad demanial a favor de la Comunidad Autónoma, dando lugar al amojonamiento, y sin que las inscripciones del Registro de la Propiedad puedan prevalecer frente a la naturaleza demanial de los bienes deslindados. Tal y como se recoge en el Art. 2 de la Ley 3/95, del Real Decreto 2876/78, por el que se aprueba el Reglamento de aplicación de la Ley 22/74 (RCL 1974, 1290) , y 1 del Decreto de 23-12-1944 de Vías Pecuniarias y señala la STS de 14-11-95 las vías pecuarias de referencia son bienes de dominio público, y por lo tanto inalienables, inembargables e imprescriptibles ( Art. 132.1 C.E .)".

Por todos estos motivos, la demanda es desestimada y se confirma la resolución sancionadora impuesta a la recurrente.

\section{2.- Sanción por aprovechamiento de aguas subterráneas}


La Sentencia no 118/2019, de 24 de abril, del Tribunal Superior de Justicia de Castilla-La Mancha, (Sala de lo Contencioso-Administrativo, Sección 2ª) JUR\2019\185059) resuelve sobre la sanción impuesta por la Confederación Hidrográfica del Júcar a una mercantil, por la comisión de una infracción del artículo 116.3.b del Real Decreto Legislativo 1/2001, de 20 de julio, por el que se aprueba el texto refundido de la Ley de Aguas, que sanciona " La derivación de agua de sus cauces y el alumbramiento de aguas subterráneas sin la correspondiente concesión o autorización cuando sea precisa".

El argumento principal de la demanda es el de que no es posible que el interesado cometiera la mencionada infracción a la vista de que este tipo de aprovechamiento no necesita concesión ni autorización, sino simple comunicación, pues se trata de un aprovechamiento privativo sujeto al régimen de los arts. 54.2 de la Ley de Aguas y 84 a 87 y 189.3.b del Reglamento de Dominio Público Hidráulico, en un acuífero no sobreexplotado. La Administración señala que la interesada solicitó, al amparo de tal régimen, la inscripción de dicho aprovechamiento, la cual fue denegada por no acreditarse suficientemente la titularidad de la parcela, y pasar en consecuencia a quedar sujeto el aprovechamiento al régimen general de autorización o concesión.

La sentencia dará la razón a la mercantil recurrente, por tratarse indubitadamente de un aprovechamiento privativo sujeto al régimen de mera comunicación:

"El interesado presentó escritura de 18 de diciembre de 2014, por la cual adquiría la totalidad de la finca; con ello se cumple la teoría del título y el modo para la adquisición de la propiedad ( art. 1462 Cc). Parece que la Confederación exige acreditar el tracto sucesivo, no sabemos remontándonos hasta qué adquirente, pero tal cosa parece claramente un exceso cuando resulta que la Administración General del Estado, de la que depende la Confederación, ha reconocido la titularidad del $100 \%$ a favor de la demandante al inscribirla catastralmente a su nombre, sin discusión sobre los títulos aportados. Carece de sentido un órgano autónomo dependiente de la misma Administración General del Estado que aceptó la documentación a unos efectos los rechace a otros efectos". 